\title{
Prismatic displacement and the remembered location of targets'
}

JOHN M. KENNEDY²

CORNELL UNIVERSITY

\begin{abstract}
Following adaptation, only the trained limb misreaches to the remembered location of targets. This suggests a change in the felt position of the trained limb, but conflicts with recent reports, and with the hypothesis that when a limb changes, the remembered location of targets encountered only by that limb undergo some change too. It suggests that information is stored independently of the mode of acquisition.
\end{abstract}

Recent experiments with prisms raise questions about the nature of memory. Data from Held and his co-workers ${ }^{3}$ (Efstathiou \& Held, 1964) suggest one view of memory. This paper outlines this view and an alternative view. An experiment is described which supports this alternative view.

Subjects (Ss) can be asked to reach out and put their fingers on a target. The target might be, for example, visible or audible, or it might be known only to touch. If a target is exposed to $S$, and then removed, $S$ can be asked to direct his movements to the remembered location of the target. So the remembered locations of targets can themselves be used as targets. These will be called "memory targets," and the target which was exposed will be called the "original target."

Held and his collaborators have studied changes in reaching movements made to various targets following training periods in which prisms were worn. They find that, following training, Ss compensate for the optical displacement due to the prism when reaching to visual targets. They do not find that the training has any such effect on memory targets.

They argue that the felt position of the arm used in training cannot be the locus of the change due to training. If it were, then the same change would appear in any task undertaken by the arm. In their studies, the same arm was used to point to both the visual targets and the memory targets. Since changes were found in only one of these tasks, an explanation solely in terms of change of felt position is untenable.

It is possible, however, that the positions of the memory targets have been altered by the training period. That is, the above results could be obtained if both the trained arm and the memory targets had undergone equal changes. But why should this happen?

Perhaps an answer lies in the way in which the $S$ met the original target, whose location is to be remembered. In the Held studies the trained limb was used in all the tasks, and so the trained limb was the only one to encounter the original target. If S's hand is actually at $45 \mathrm{deg}$ to the median plane, and is touching a target, then, obviously, the target is at $45 \mathrm{deg}$ to the median plane. Let the target be removed. If $S$ now becomes convinced that his hand is directly in front of him, it may seem to him that the target was actually in front of him, too. So both his judgment of the position of his hand, and his judgment of the position of the target have changed. Now, if S tries to touch the place where the target was, he will try to put his hand in the median plane. To do this, he puts his hand back where it was, that is, at $45 \mathrm{deg}$ to the median plane. To an $O$, it looks as though no change has occurred.

Yet there have been two changes, and so in prism studies there may be two problems for $\mathrm{S}$ : first, to be responsive to the new relation, and second, to utilize the information gleaned when the old relation was in force. It is possible that the $S$ may come to use the new relation appropriately, and that his use of previously obtained information is disturbed. If it is true that previously obtained information is reinterpreted, then it seems that the stored information is closely dependent on the manner in which it was originally acquired.

There is a significant alternative to this hypothesis. Events in the world are, on the whole, multiply specified (cf. Gibson, 1966). It might well be that organisms make use of the fact that varied information specifies one event. A fire, for example, means visible flames, the smell of smoke, and the crackle of burning materials. Perhaps organisms could retain the knowledge that a fire had occurred, and yet forget the way in which they discovered this. Perhaps they do this just as much as they may retain the sense of a sentence while forgetting the details of syntax (cf. Sachs, 1967).

There are, thus, two hypotheses: (a) Stored information is dependent on the mode of acquisition; and (b) stored information is independent of the mode of acquisition. Of these two, only the first explains Held's result. The explanation would be that the trained limb has changed its location with respect to the body, and in so doing has altered the remembered location of those targets located only by that arm. To test the explanation further, and more directly, it is necessary to find a task which will reveal the changes in the location of the memory target. Showing a change would clearly be better than showing a nonchange and then explaining this nonchange as the result of two changes, which cancel each other. One test is to ask the untrained limb to reach to the memory target. It has not been trained and it can be assumed to have maintained its judged position with respect to the body. So, any changes in reaching, after the training, are due to a change in the location of the memory target with respect to the body.

For such a test in the present experiment, Ss learned the position of a target with one arm. This arm was the only part of the body which encountered the target. After that, the same arm was used while reaching for a visible target, which was subject to prismatic displacement. During this period, the training period, a target light was presented and the Ss reached out to put their fingers on the light. All that $S$ ever saw was the target light, and, at termination of reach, the index finger.

Following the training period half of the Ss reached with the trained arm (the ipsilateral group). The other Ss reached with the untrained arm (the contralateral group).

\section{SUBJECTS}

Subjects were female, obtained by the Canadian Defense Research Establishment, Toronto. They were rejected as too variable if the ranges of their pretests, in both experimental and control sessions, were too great. The ranges were added together, and if the total was $16 \mathrm{deg}$ or more, $\mathrm{S}$ was rejected.

Optical displacement can be to the left or right; training can be applied to the left or right arm; the memory target can be to left or right of the straight-ahead. This produces eight possible combinations, or cells. To diminish risk of some artifact, Ss were distributed one per cell; eight Ss were placed in each of two experimental groups.

\section{APPARATUS}

The apparatus used was designed and built by I. P. Howard, 
with the addition of a component to produce a memory target. This component was a plastic slide, carrying two grooves, one narrowing from the left, and the other from the right. In the center was an indentation about $1 / 4$-in. square, serving as target. Groove width and direction indicated to $\mathrm{S}$ the extent and direction of any error made in reaching for the target. When the plastic slide was in place, the indentation was called the "touch target," since its position was given by touch alone. The slide could be removed, and $S$ could then be instructed to reach to the same location. This was called "reaching for the memory target," since the location was given by memory alone.

The Howard apparatus controls head position, amount of displacement, visual direction of the target, and physical direction of the target. Visual direction is controlled by a variable prism, whose power at any moment is shown on a scale. Knowing the power, one can place the physical target such that it is visually straight-ahead of $\mathrm{S}$. The prism is altered by a motor, whose action, every $10 \mathrm{sec}$, is a signal for $S$ to reach out and put his finger on the target. Every third action by the motor increases prism displacement; an increase from 0 deg to $15 \mathrm{deg}$ takes about $7 \mathrm{~min}$ to achieve. Since each displacement is less than the usual error made by $S$, he is unlikely to detect the amount and direction of final displacement. Howard has called this progressive increase in displacement a "prism shaping procedure" (Howard, in press).

The visual target is a luminous line, which appears randomly in one of three positions per trial, either straight-ahead, or $5 \mathrm{deg}$ to the left or right of straight-ahead. This discourages stereotypy of movement.

Visual knowledge of error can be given by opening a small gap that reveals S's finger on termination of reach. During testing the gap is closed, and the touch target is not present, so there is no knowledge of results. During testing nothing is visible to $S$. During training only the luminous line and S's finger on termination of reach are visible.

The touch target is placed at $10 \mathrm{deg}$ to one side of the median plane when $S$ is being trained to reach to one location. When the touch target is removed, the location becomes the memory target.

\section{PROCEDURE}

In pretraining, Ss are given familiarity with the touch target, memory target, visual target, and also with absence or presence of knowledge of error. Half of the Ss use one arm in the remainder of the experiment (ipsilateral group) and the others use one arm for testing and the contralateral for training (contralateral group).

All Ss go through a procedure to control for the asymmetry about the median plane of training actions. This is necessary to control for any effects due to the actions themselves, independent of their relationship to targets. This is followed by a rest period of at least $15 \mathrm{~min}$ and then by the experimental procedure (see Table 1).
Table 1

Procedure

$\begin{array}{llll}\begin{array}{ll}\text { 1. Pretraining } \\ \text { 2. Control }\end{array} & \begin{array}{l}\text { 1. Pretest } \\ \text { (Memory target) }\end{array} & \begin{array}{l}\text { 2. Training } \\ \text { (Touch target) }\end{array} & \text { 3. Posttest } \\ & \text { (Memory target) }\end{array}$

Rest Period

3. Pretraining

4. Experiment 1. Pretest 2. Training 3. Posttest

(Memory target) (Visual target) (Memory target)

The experimental procedure consists of reaching to a visible target, with opportunity to detect and correct for error, using visual guidance. Displacement due to the prism increases during this period, but the target is moved so that its average position remains the visual straight-ahead. There is, thus, no need for a control for visual asymmetry.

In the control for asymmetry of movements about the median plane, a touch target is used. This moves in the same manner as the visual target is moved in the experimental procedure, so that $\mathrm{S}$ has to make similar movements in the two procedures. As there is no visual target in the control procedure, there is no need for any change in the S's coordination.

Maximum displacement is achieved in 50 trials. An additional 10 are given to confirm training.

Pretest is begun when $S$, in six successive practice trials, comes within 2 deg left or right of the touch target. Pretest and posttest are 10 successive trials to the memory target.

\section{RESULTS}

Table 2 contains the results of subtracting any change in the control procedure, from pretest to posttest, from any such change in the training procedure. The resultant figures are the shifts in reaching to the memory target after training with prismatic displacement. On the Wilcoxon test only the results of the ipsilateral group are different from zero at the 5\% level, on a two-tailed test.

\section{DISCUSSION}

The contralateral group should reveal changes in the location of the memory target. The ipsilateral group is comparable to the Held groups. The Held data would be confirmed if the ipsilateral group were not different from zero. In fact, they are different from zero, in the direction of compensation for prism displacement. The hypothesis that Held's data suggest would be confirmed if, first, the ipsilateral group were not different from zero, and, second, if the contralateral group were different from zero in the direction of compensation for prism displacement. Neither of these predictions is confirmed.

The change in the ipsilateral group-using the trained limbs-could be a change in position sense. The absence of change in the results from the contralateral group suggests that

Table 2

Shifts in Localization of the Memory Target

\begin{tabular}{|c|c|c|c|c|c|c|c|c|}
\hline \multirow{4}{*}{$\begin{array}{l}\text { Mem. T. } \\
\text { I. GP. }\end{array}$} & \multicolumn{3}{|c|}{ Displacement to S's } & Left (L) & \multicolumn{4}{|c|}{ Displacement to S's Right (R) } \\
\hline & \multicolumn{2}{|c|}{ R Arm } & \multicolumn{2}{|c|}{ L Arm } & \multicolumn{2}{|c|}{ R Arm } & \multicolumn{2}{|c|}{ L Arm } \\
\hline & $10 \operatorname{deg} L$ & $10 \operatorname{deg} R$ & $10 \operatorname{deg} L$ & $10 \operatorname{deg} R$ & $10 \operatorname{deg} L$ & $10 \operatorname{deg} R$ & $10 \operatorname{deg} L$ & $10 \operatorname{deg} R$ \\
\hline & $+12,83$ & -3.83 & +8.92 & +8.73 & -0.25 & +0.88 & +6.24 & +4.5 \\
\hline C.GP. & -0.08 & -3.41 & +3.40 & +2.31 & -0.01 & +6.17 & -15.74 & -9.75 \\
\hline
\end{tabular}

Positives compensate for prism displacement.

Figures are in degrees.

Mem. T. = Memory Target

I. GP. = Ipsilateral Group

C. GP. = Contralateral Group 
the memory target has not moved. So the results can be explained by two hypotheses: first, that recalibration of position sense has occurred, and, second, that even if targets are encountered by only one part of the body, they are not localized primarily in relation to that part. It seems that targets are localized with respect to some more inclusive system. It is not clear how this system is to be described. It might be a unified perceptual world, or perhaps a system of directions, or positions, with respect to some major body axes. This experiment indicates only that the localization is not dependent on some restricted part of the body, not even that part that originally discovered the target.

Since this experiment was completed, a comparable, unpublished, study by Hamilton and Hillyard was made available. They found compensatory changes in the trained limb, and none in the untrained limb. In their study, and in the present study, no chest harness was used, while in the Efstathiou and Held experiment a chest hamess was worn by all Ss. Hamilton and Hillyard suggest that this is critical, for the harness would accentuate "tactile cues associated with tension or pressure in the upper arm ... . Such cues would not be affected by adaptation."

Hamilton and Hillyard's suggestion can explain the difference between the present study, plus their own study, and the Held studies. Finally, their own study and the present one suggest that acquisition of information, and use of previously acquired information can be considered as different problems, and that stored information can be independent of its mode of acquisition.

\section{REFERENCES}

EFSTATHIOU, A., \& HELD, R. Cross modal transfer of adaptation to eye-hand rearrangement. Paper presented at the meeting of the Eastern Psychological Association, 1964.

GIBSON, J. J. The senses considered as perceptual systems. Boston: Houghton Mifflin, 1966.

HOWARD, 1. P. Displacing the optical array. In S. J. Freedman (Ed.), The neuropsychology of spatially oriented behavior. Homewood, III.: Dorsey Press, in press.

SACHS, J. S. Recognition memory for syntactic and semantic aspects of connected discourse. Perception \& Psychophysics, 1967, 2, 437-442.

\section{NOTES}

1. The research for this paper was undertaken at York University, Toronto, and at the Defense Research Establishment, Toronto.

2. Address: Psychology Research Laboratories, Cornell University, Ithaca, N.Y. 14850.

3. See J. A. Bauer, Jr., M. Greene, \& R. Held, Prism-induced shifts in reaching for targets localized by three sensory modalities: A further study of intermodal transfer. Unpublished manuscript, 1963.

(Accepted for publication November 15, 1968.) 